\title{
Neural Network dan Particle Swam Optimization untuk Penunjang Keputusan Antipasi Mahasiswa Pra Lulus Bekerja Sesuai Bidang Neural Network and Particle Swam Optimization to Support Anticipation Decisions for PreGraduated Students Working according to Fields
}

\author{
Very Kurnia Bakti ${ }^{1}$, Dairoh Dairoh ${ }^{2}$, Muhammad Naufal $^{3}$
}

Politeknik Harapan Bersama, Indonesia

\section{Informasi Artikel}

\section{Genesis Artikel:}

Diterima, 14 April 2021

Direvisi, 18 Mei 2021

Disetujui, 3 September 2021

\section{Kata Kunci:}

Lulusan

PSO

Neural Network

Algoritma

Politeknik Harapan Bersama

Keywords:

Graduates

PSO

Neural Network

Algorithm

Politeknik Harapan Bersama

\begin{abstract}
ABSTRAK
Lulusan di Perguruan Tinggi yang bekerja sesuai bidang belum ideal dalam tiga tahun terakhir, salah satunya di Politeknik Harapan Bersama. Hal ini masih menunjukkan keselarasan horizontal. Sehingga pertanyaaan nya adalah kenapa hal tersebut terjadi dan disebabkan oleh apa saja yang dapat menentukan kualitas lulusan yang bekerja tidak sesuai bidang. Untuk itu, dibuat sebuah model yang dapat digunakan untuk dapat melihat pola lulusan, agar lulusan bisa bekerja sesuai bidang keilmuan. Data set yang digunakan adalah mahasiswa lulusan tahun 2017 hingga 2019 sebanyak 1281 data. Model tersebut menggunakan kombinasi antara Algoritma Neural network dengan PSO (Particle Swam Optimization). Diperoleh perbandingan akurasi model kombinasi antara Neural Network dengan PSO sebesar $71.51 \%$ untuk PSO, sedangkan dengan menggunakan metode Neural Network sebesar $64.32 \%$. Dari hasil tersebut akurasi Neural Network dengan menggunakan optimasi algoritma PSO lebih besar dibandingkan tanpa algoritma PSO hanya menggunakan Neural Network.
\end{abstract}

\section{ABSTRACT}

Graduates in tertiary institutions who work by their fields have not been ideal in the last three years, one of which is at the Joint Hope Polytechnic. It still shows horizontal alignment. So the question is why does this happen and is caused by anything that can determine the quality of graduates who work not under the field. For this reason, a model is created that can be used to be able to see the patterns of graduates, so that graduates can work according to their scientific fields. The data set used was 1281 graduate students from 2017 to 2019. The model uses a combination of the Neural Network Algorithm and PSO. The comparison of the combination model accuracy between the Neural Network and PSO is $71.51 \%$ for PSO while using the Neural Network method is $64.32 \%$. The results, the accuracy of the Neural Network using the PSO algorithm optimization is greater than without the PSO algorithm using only the Neural Network.

\section{Penulis Korespondensi:}

Very Kurnia Bakti,

Program Studi Teknik Komputer,

Politeknik Harapan Bersama,

Email: verykurniabakti@gmail.com 


\section{PENDAHULUAN}

Kemajuan dalam bidang teknologi komputer memudahkan semua dalam segala aspek, salah satunya dalam perhitungan yang rumit dalam traffic serta jumlah data yang banyak dan besar. Fenomena sekarang yang dikenal dengan big data ini menguntungkan sebuah institusi yang dapat dijadikan dalam mengambil pertimbangan untuk membuat kebijakan ataupun keputusan penting. Pengambilan keputusan dapat memanfaatkan algoritma sebagai alternatif atau penunjang [1]. Salah satunya sebagai penunjang keputusan dalam lulusan disebuah Perguruan Tinggi yang sesuai bidang lulusan. Persaingan kelulusan mahasiswa di sebuah perguruan tinggi dalam meluluskan mahasiswa serta mendapatkan pekerjaan sesuai bidang saat ini menjadi piroritas pengelola perguruan tinggi untuk dapat mempersiapkan nantinya, agar mampu bekerja sesuai bidang. Sehingga perlu dilakukan evaluasi akan performa lulusan yang berkerja sesuai bidang dengan menerapkan data mining. Salah satunya yang dilakukan oleh Meinanda dkk (2009) menerapkan data mining dalam memprediksi lamanya waktu belajar mahasiswa dengan menggunakan algoritma Neural Network [2] data set yang digunakan adalah data training dari data mahasiswa lulusan masa lalu dengan data aktual lulusan mahasiswa. Selain itu data mining dengan menggunakan algoritma Neural Network juga digunakan untuk melakukan evalusi pada salah satu program studi terhadap kelulusan mahasiswa yang berdasarkan pada IP yang diperoleh terhadap lamanya kelulusan dari mahasiswa [3]. Salah satu perguruan tinggi vokasi swasta di Jawa Tengah yakni Politeknik Harapan Bersama. Berdasarkan data di bagian akademik Politeknik Harapan Bersama bahwa jumlah mahasiswa tiga angkatan sebanyak 5.000 mahasiswa diketahui berdasarkan data dari tracer studi bahwa banyak lulusan Politeknik Harapan Bersama yang bekerja masih tidak sesuai dengan bidang ilmu. Diperoleh Angka kelulusan pada tiga tahun terakhir di tracer study Politeknik Harapan Bersama kurang dari 80\%. Hal ini, menunjukkan bahwa lulusan Mahasiswa Politeknik Harapan Bersama masih dalam keselaran horizontal dan belum mencapai nilai ideal. Sehingga muncul pertanyaan apa yang menyebabkan kenapa hal tersebut terjadi serta dipengaruhi apa sajakah yang dapat menentukan kualitas lulusan yang mengakibatkan lulusan tidak bekerja sesuai bidang [4]. Sehingga akan dilakukan model algoritma dengan metode optimal Neural Network dengan PSO untuk penunjang keputusan antipasi mahasiswa setelah lulusan yang bekerja sesuai bidang pada lulusan Politeknik Harapan Bersama.

Neural Network merupakan sebuah tiruan dari syaraf yang dalam bentuk sebuah model non liniear rumit serta dibangun dengan individu mirip dari perilaku dari model refgresi. Sebuah Neural Network ini digambarkan seperti sebuah grafik lalu ke beberapa sub dari grafiknya. selain itu, diddalamnya terdapat integritas yang mirip gerbang sebuah logika pada sebuah struktur dijaringan neuron yang dirancang lebih dulu secara terperinci menggunakan algoritma genetika untuk memprediksi lulusan mahasiswa. memperdikasi kelulusan mahasiswa, diperoleh hasil akurasi dengan Neural Network nya sebesar $71.48 \%$ kemudian nilai akurasi Neural Network menggunakan algoritma genetika didapatkan $99.33 \%$ [5]. Dalam model Neural Network mesin pembelajarannya ini yakni merupakan sebuah aspek dari sebuah pembelajaran yang menirukan pada sebuah pengalaman di masa yang lalu guna mampu memprediksi kejadian di masa nanti [6]. Definisi dari sebuah particle swarm optimization adalah salah satu dari sebuah algoritma dimana pencariannya menggunakan banyaknya individu yang dikelompokan dalam sekelompok [7]. Hal Algoritma PSO adalah otimasi algoritma yang dapat mudah untuk dipelajari dan dipahami, selain itu dipandang dapat menghasilkan, sederhana dan menunjukkan hasil kerja yang sudah memadai serta handal [8]. Pada particle PSO berhubungan dengan suatu velocity maksudnya bahwa particle-particle didalam PSO bergerak menelusuri sebuah dengan velocity secara dinamis yang disesuaikan pada history perilaku [7]. Didalam PSO menggunakan konsep pbest dan gbest yang mirip dengan operasi crossover pada genetic algorithma (GA) [9]. PSO itu sendiri juga merupakan algoritma yang menirukan perilaku sosial yang berupa tindakan dari individu serta dari pengaruh lainnya dalam kelompok. Sebagai contoh adalah se-ekor burung dan kumpulan dari kawanan burung [7]. Metode algoritma yang dapat dijadikan sebagai fitur seleksi dalam melakukan pengolahan data yakni PSO (Particle Swam Optimization). Seperti diketahui bahwa algoritma PSO memiliki ciri khas yaitu kemampuan perhitungan dengan metode optimasi yang berdasarkan pada populasi diantaranya berupa genetic algorithma (GA) selain itu metode PSO digambarkan pada dasar perilaku kawanan burung yang digambarkan dengan perilaku social yang terdiri atas perilaku individu dan orang lain di dalam kelompok. . Selain itu PSO juga memiliki karakteristik lain yakni berupa karateristik non linear dan non different ability, multiple optime, dimensi serta dimensi besar yang berdasarkan pada adaptasi yang diturunkan dari teori psikologis sosial [10].

Penelitian [11] telah memprediksi lulusan tepat waktu pada mahasiswa menggunakan PSO dan algoritma C.45 disebuah perguruan tinggi, dengan hasil untuk lulusan di tahun 2000 hingga 2003 pada AMIK PPMI di Tangerang ini diperoleh untuk nilai akurasi dengan PSO $87.56 \%$ mengalami peningkatan $1.10 \%$ dibanding metode decision tree yakni menjadi 87.55\%. Hasil dari dengan PSO nampak bahwa PSO mampu mengidentifikasi atribut yang tidak berobot dan mampu meningkatkan nilai akurasi. Penelitian [12] memprediksi mahasiswa pada lulusan tepat waktu dengan membandingkan 4 algoritma, dengan nilai accuracy $74.08 \%$, sedangkan untuk masing-masing 4 algoritma yakni dengan didapatkan AUCnya 0,788 dan penambahan pada fitur PSO mengalami peningkatan yakni pada nilai akurasi tertinggi di decision tree (C.45) diperoleh 5.21\% sedangkan untuk nilai pada nave bayes yang terendah sebesar 2.13\%. Penelitian [13] telah melakukan analisis prediksi pada lulusan mahasiswa dengan decision tree dengan PSO pada data mahasiswa lulusan ditahun 2000-2003 hasilnya bahwa PSO, diperoleh hasil terjadi kenaikan akurasi sebesar $1.01 \%$ dengan nilai 87.56 dibandingkan hasil dari decision tree didaptkan $86.55 \%$ Hal ini menunjukkan bahwa penggunaan PSO mampu memilih atribut 
yang tidak dipakai dan tidak berbobot. Oleh karena itu, metode PSO ada peningkatan akurasi tersebut dapat digunakan untuk perguruan tinggi agar dapat menghindari kelulusan mahasiswa tidak tepat waktu. Penelitian [14] telah melakukan proses implementasi algortima Neural Network untuk prediksi tingkat kelulusan mahasiswa. Hasilnya cara kerja dari sebuah algoritma Neural Network sama seperti MLP, namun pada Neural Network setiap neuronnya dalam bentuk 2 dimensi dan diperoleh akurasi prediksi tingkat kelulusan sebesar 98.27\%. Dari permasalahan dan uraian penelitian sebelumnya diatas maka pada penelitian ini dilakukan metode kombinasi antara Neural Network dengan menggunakan fitur selektif berupa PSO. Sehingga dari penelitian ini diperoleh output yang dapat digunakan sebagai penunjang keputusan untuk mengetahui model akurasi lulusan yang sesuai bidang disuatu perguruan tinggi secara akurat sebagai antipasi mahasiwa pra lulusan yang bekerja sesuai bidang $[15,16]$.

\section{METODE PENELITIAN}

\subsection{Data Penelitian}

Pada penelitian ini dipakai data berupa data sekunder dari data tracer study, yang diambil dari sistem tracer study Politeknik Harapan Bersama untuk tahun lulusan 2017-2019 yang terkumpul. Adapun data yang terkumpul dalam penelitian ini sebanyak 1281 data dengan perbandingan label 657 selaras atau 52\% dan 624 atau $48 \%$ tidak selaras. Table 1 merupakan atribut yang digunakan dalam penelitian ini.

Tabel 1. Atribut yang digunakan dalam Penelitian

\begin{tabular}{|c|c|c|c|}
\hline No & Attribute & Range & Keterangan \\
\hline 1 & Nim (id) & - & nim mahasiswa (ID) \\
\hline 2 & Lulusan & 2017-2019 & tahun lulus mahasiswa \\
\hline 3 & Kode Prodi & - & Kode program studi \\
\hline \multirow[t]{2}{*}{4} & IPK & $2.00-4.00$ & nilai induk prestasi kumulatif (IPK) \\
\hline & & & yang didapat lulusan \\
\hline 5 & Lulus tepat waktu & 01 & status lulus (1) tepat waktu atau (0) tertunda \\
\hline \multirow[t]{2}{*}{6} & Mendapat beasiswa & 01 & pernah memperoleh bantuan beasiswa \\
\hline & & & selama kuliah 0 (tidak pernah), dan 1 (pernah) \\
\hline 7 & Jenis kelamin & $0-1$ & 0 (perempuan) 1 (laki-laki) \\
\hline 8 & Umur & $18-50$ & Usia lulusan \\
\hline 9 & Kelas & $0-1$ & 0 (ekstensi) 1 (reguler) \\
\hline \multirow[t]{2}{*}{10} & Tempat KP & $1-3$ & Tempat melakukan kerja praktek KP \\
\hline & & & 1 (pemerintahan), 2 (sekolahan), 3 (swasta) \\
\hline \multirow[t]{2}{*}{11} & Sesuai bidang (label) & $0-1$ & kesesuaian profil lulusan dengan pendidikan \\
\hline & & & yang ditempuh 0 tidak sesuai, dan 1 sesuai \\
\hline
\end{tabular}

\subsection{Processing Data}

Pada processing data penelitian ini dilakukan beberapa tahapan antara lain yang tersaji seperti pada Gambar 1 dapat dijelaskan uraian dalam pelaksanaan processing data penelitian ini antara lain sebagai berikut:

1. Pengolahan data set awal, data set dalam bentuk data pengujian (testing) dan pembelajaran (training), masing masing partikel mewakili subset fitur yang merupakan solusi dari calon data set ditransformasikan kedalam rentang 0 dan 1 , kemudian data set dibagi menggunakan metode 3-fold cross validation, Selanjutnya data set diuji dengan model Neural Network dan memvalidasi model yang dihasilkan untuk mendapatkan akurasi model, jika kriteria akurasi memenuhi akan menghasilkan fitur yang di optimalkan, jika kriteria akurasi tidak terpenuhi maka mencari atribut yang tidak di optimal, sehingga menemukan atribut yang tidak optimal maka akan dihilangkan sehingga model optimasi Neural Network didapatkan, kemudian dilakukan pengujian ulang dengan model Neural Network .

2. Eksperimen dan pengujian metode: Pengujian data dilakukan menggunakan metode Neural Network dengan algoritma PSO yang akan menghasilkan akurasi dalam proses penentuan lulusan bekerja sesuai bidang. Tahap uji menggunakan teknik validasi yang bertujuan untuk mendapatkan nilai accuracy dan data set diuji menggunakan metode yang diusulkan melalui pemrograman Matlab [17].

3. Evaluasi dan validasi, tahap evaluasi dan validasi dengan pengujian, metode yang diterapkan adalah pengujian dari metode Neural Network yang digabungkan algoritma PSO dapat terlihat tingkat nilai akurasi yang didapat dari perhitungan confusion matriks, sehingga tujuan penerapan metode Neural Network dengan algoritma PSO untuk menentukan lulusan bekerja sesuai 
dengan bidangnya dan model validasi yang digunakan adalah metode 3-fold cross validation untuk mempelajari dan menguji data. Model data dibagi menjadi tiga bagian yang sama. Selanjutnya dilakukan proses pembelajaran (training) sebanyak tiga kali. Setiap kalinya dipilih bagian lain dari data set untuk pengujian (testing) dan menggunakan dua bagian yang tersisa untuk pembelajaran (training). Adapun model tiga-cross-validation yang digunakan seperti pada Tabel 2.

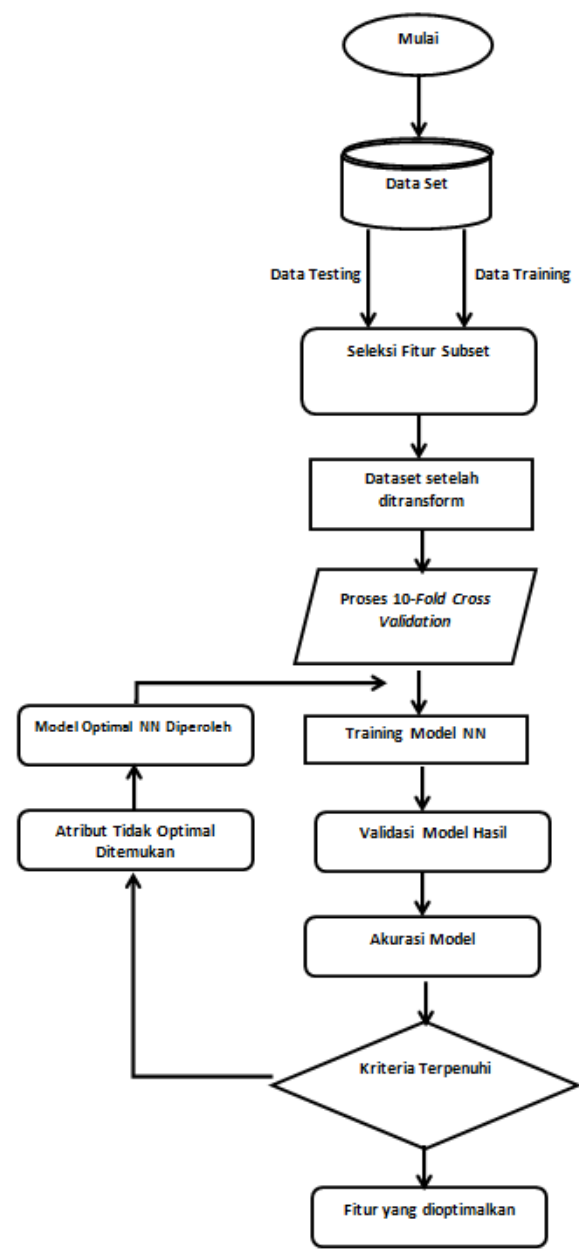

Gambar 1. Pelaksanan processing data

Tabel 2. Ilustrasi 3 Fold Cross Validation [18]

\begin{tabular}{cc}
\hline Validasi Ke-n & Dataset \\
\hline 1 & \\
2 & \\
3 & \\
\hline
\end{tabular}

Metode 3-fold cross validation menjadi metode standar dalam pembelajaran (training) dan pengujian data. Penggunaan data set bersifat publik menjadikan penelitian yang dapat di teliti ulang, tidak dapat dipungkiri, dan dapat diverifikasi [18]. Model evaluasi yang diterapkan yaitu penentuan akurasi hasil dari confusion matrix yang digunakan untuk melakukan evaluasi terhadap model klasifikasi berdasarkan perhitungan objek testing yang ditabulasikan kedalam tabel dimana akan diprediksi benar dan tidak benar. Confusion matriks merupakan data set hanya memiliki dua kelas, satu kelas sebagai positif dan kelas yang lain negatif. Terdiri dari empat sel yaitu true positives (TP), false positives (FP), true negatives (TN) dan false negatives (FN) [19] seperti pada Tabel 3. 
Tabel 3. Confusion matriks untuk 2 model [19]

\begin{tabular}{llll}
\hline Classification & \multicolumn{2}{c}{ Predicted class } \\
\hline observed class & & class $=$ yes & class $=$ no \\
& class $=$ yes & $\mathrm{a}$ & $\mathrm{b}$ \\
& & (true positive $-\mathrm{TP})$ & $($ false negative $-\mathrm{FN})$ \\
& class $=$ no & $\mathrm{c}$ & $\mathrm{d}$ \\
& & $($ false positive $-\mathrm{FP})$ & (true negative $-\mathrm{TN})$ \\
\hline
\end{tabular}

Dan untuk menghitung akurasi digunakan persamaan (1) [13].

$$
\text { Akurasi }=\frac{(T N+T P)}{(T N+F N+T P+F P)}
$$

\section{HASIL DAN ANALISIS}

Pada penelitian ini untuk proses pengolahan menggunakan Matlab dan proses analisis menggunakan RapidMiner.

\subsection{Hasil}

Data yang didapat dari penelitian ini bersifat privat diambil dari Bagian Akademik Politeknik Harapan bersama dan data tracer study. Dalam penelitian ini digunakan metode berupa Neural Network pada algoritma PSO. Hasil dari penelitian bertujuan untuk mengetahui nilai akurasi apakah peran kerja praktek semasa kuliah lebih efektif dalam memprediksi lulusan bekerja sesuai bidang menggunakan penerapan dari sebuah Neural Network menggunakan algoritma PSO. Adapun hasil bobot atribut yang diperoleh dari pengolahan data pada Tabel 4.

Tabel 4. Nilai Bobot yang diperoleh

\begin{tabular}{ll}
\hline Attribute & Bobot \\
\hline Tahun lulusan & 0.338 \\
Kode prodi & 0.192 \\
IPK & 0.511 \\
Lulus tepat waktu & 0.368 \\
Beasiswa & 1 \\
Jenis Kelamin & 0 \\
Umur & 0.432 \\
Kelas & 0.427 \\
KP & 0.998 \\
\hline
\end{tabular}

Tabel 4 menunjukkan bahwa atribut yang berpengaruh terhadap lulusan sesuai bidang adalah tahun lulusan, kode prodi, IPK, lulus tepat waktu, beasiswa, umur, kelas dan KP. Sedangkan atribut yang tidak berpengaruh yaitu Jneis Kelamin. Hasil dari experiment yang dilakukan pada data set terbentuk arsitektur Neural Network seperti pada Gambar 2.

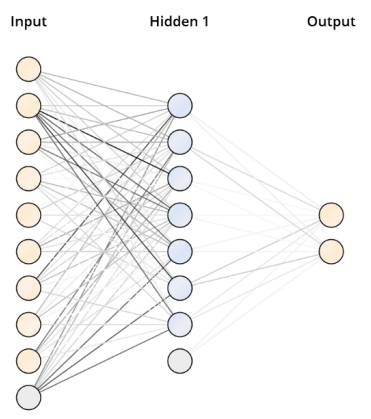

Gambar 2. Hasil aristek Neural Network 
Pada Gambar 2 model algoritma Neural Network dilakukan proses training dengan komposisi hiden layer 7, training cycles 500, learning rate sebesar 0.1 dan momentum 0.9. Sehingga hasil yang diperoleh pada Gambar 2 dengan metode Neural Network menghasilkan tiga lapisan (layer) yang terdiri lapisan input terdiri dari sembilan node dan satu node bias. Lapisan yang kedua merupakan lapisan yang tak tampak (hidden layer) terdiri tujuh node dan satu node bias. Lapisan ketiga merupakan output layer terdiri dari dua node yakni atribut kelas 0 dan 1.

\subsection{Pengujian}

Pengujian model dilakukan setelah dilakukannya eksperimen implementasi Neural Network dan Neural Network berbasis particle swarm optimization hal tersebut dilakukan dengan cara membandingkan nilai accuracy dan dalam menentukan tingkat keakurasian dari perbandingan tersebut maka confusion matrix yang didapat baik model Neural Network itu sendiri ataupun Neural Network berbasis particle swarm optimization berdasarkan 16384 data yang diolah, dengan hasil perbandingan pada Tabel 5 dan Tabel 6.

Tabel 5. Hasil Nilai Akurasi dengan Neural Network

\begin{tabular}{llll}
\hline \multicolumn{4}{c}{ Akurasi 64.32\% } \\
\hline & true 1 & true 0 & class precision \\
\hline prediksi 1 & 784 & 320 & $71.01 \%$ \\
prediksi 0 & 137 & 40 & $22.60 \%$ \\
class recall & $85.12 \%$ & $11.11 \%$ & \\
\hline
\end{tabular}

Tabel 5 dapat diklasifikasikan pada true positive (TP) sebesar 784 record, false negative (FN) 137 record, true negative (TN) 40 record dan false positive (FP) 320 Record. Dari hasil klasifikasi menunjukkan bahwa, tingkat akurasi dengan menggunakan algoritma Neural Network adalah sebesar $64.32 \%$ sedangkan untuk pengujian data dengan model Neural Network yang dioptimasi dengan algoritma PSO hasilnya seperti pada Tabel 6.

Tabel 6. Hasil nilai akurasi PSO dengan NN

\begin{tabular}{llll}
\hline \multicolumn{4}{c}{ Akurasi 71.51\% } \\
\hline & true 1 & true 0 & class precision \\
\hline prediksi 1 & 915 & 359 & $71.82 \%$ \\
prediksi 0 & 6 & 1 & $14.29 \%$ \\
class recall & $99.35 \%$ & $0.28 \%$ & \\
\hline
\end{tabular}

Berdasarkan Tabel 6 dapat diklasifikasikan true positive (TP) sebesar 915 record, false negative (FN) 359 record, true negative (TN) 1 record dan false positive (FP) 6 Record. Dari hasil pengujian data dengan model Neural Network yang dioptimasi dengan PSO diperoleh bahwa dengan menggunakan algoritma PSO ini mempunyai kelebihan, hal ini terlihat bahwa algoritma tersebut dapat mengoptimalkan akurasi. Dengan demikian, metode Neural Network dengan algoritma PSO dapat digunakan untuk melakukan klasifikasi terhadap lulusan sesuai bidang. Hasilnya menunjukan bahwa model kombinasi Algoritma PSO dapat menghitung dengan karakteristik metode optimasi berbasis populasi seperti algoritma genetika (GA). PSO berdasarkan pada perilaku sekawanan burung [7], dimana perilaku sosial tersebut terdiri dari tindakan individu berpengaruh terhadap individu lain dalam suatu kelompok [10], sedangkan jaringan saraf merupakan sistem adaptif yang mampu mengubah strukturnya untuk menyelesaikan masalah berbasis eksternal. dan informasi internal yang berjalan melalui jaringan. Hasil klasifikasi menunjukkan tingkat akurasi dengan menggunakan algoritma Neural Network adalah sebesar $71.51 \%$. Dari hasil akurasi yang diperoleh diatas bahwa Neural Network dengan algoritma PSO dapat digunakan untuk melakukan klasifikasi terhadap lulusan sesuai bidang dan hasilnya menunjukan bahwa model kombinasi Algoritma PSO dapat menghitung dengan karakteristik metode optimasi berbasis populasi seperti algoritma genetika (GA) untuk dapat menunjang dalam keputusan antipasti mahasiswa seblum bekerja. penggunaan metode NN dapat dilihat seperti pada Gambar 3 . 


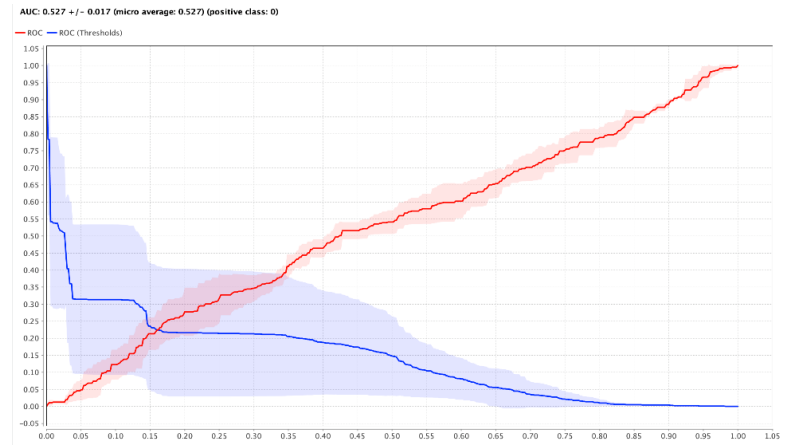

Gambar 3. Grafik dari implementasi NN

Untuk penggunaan penggabungan Neural Network dengan PSO dapat dilihat pada Gambar 4.

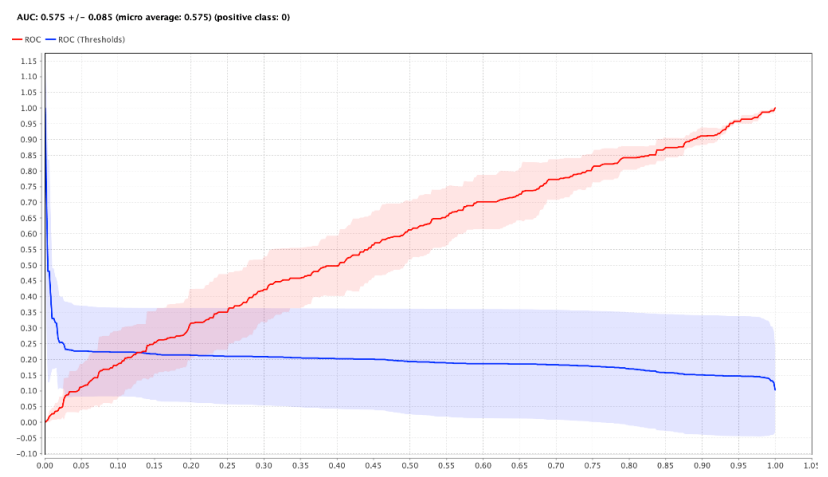

Gambar 4. Grafik dari penggunaan NN dengan Optimalisasi PSO

\section{KESIMPULAN}

Diperoleh tingkat akurasi perbandingan untuk model Neural Network dengan mengunakan aplikasi RapidMiner yakni diperoleh nilai akurasi Neural Network dengan optimasi algoritma PSO 71.51\% sedangkan dengan hanya menggunakan Neural Network saja diperoleh 64.32\%. Maka dapat dikatakan bahwa nilai akurasi Neural Network dengan menggunakan optimasi algoritma PSO lebih besar dibandingkan tanpa algoritma PSO hanya menggunakan Neural Network.

\section{UCAPAN TERIMA KASIH}

Peneliti mengucapakan terimakasih untuk P3M dan bagian dari divisi alumni Politeknik Harapan Bersama yang memberikan fasilitas dalam pelaksanaan penelitian ini.

\section{REFERENSI}

[1] Y. Guo, "A Comprehensive Review of Deep Learning Methods and Applications," in Deep learning for visual understanding. Leiden University, 2017.

[2] M. H. Meinanda, M. Annisa, N. Muhandri, and d. K. Suryadi, "Prediksi Masa Studi Sarjana dengan Artificial Neural Network," Internetworking Indonesia Journal, vol. 1, no. 2, pp. 31-35, 2009.

[3] A. F. Mutiara Ayu Banjarsari, H. Irwan Budiman, "Penerapan K-Optimal pada Algoritma KNN untuk Prediksi Kelulusan Tepat Waktu Mahasiswa Program Studi Ilmu Komputer FMIPA UNRAM Berdasarkan IP Sampai dengan Semester 4," Klik Kumpulan Jurnal Ilmu Komputer, vol. 2, no. 2, pp. 159-173, 2015.

[4] V. Kurnia Bakti, M. Noval, and E. Purnomo Bayu Aji, “Sistem Pre Kompilasi Data Tracer Studi Online Ditjen Belmawa 
Ristekdikti(Studi Kasus: Politeknik Harapan Bersama)," Jurnal Informatika: Jurnal Pengembangan IT, vol. 2, no. 1, pp. 50-53, 2017.

[5] I. Ali and L. Sularto, "Optimasi Parameter Artificial Neural Network Menggunakan Algoritma Genetika untuk Prediksi Kelulusan Mahasiswa,” Jurnal ICT : Information Communication \& Technology, vol. 18, no. 1, pp. 54-59, aug 2019.

[6] M. Inthachot, V. Boonjing, and S. Intakosum, "Artificial Neural Network and Genetic Algorithm Hybrid Intelligence for Predicting Thai Stock Price Index Trend," Computational Intelligence and Neuroscience, vol. 2016, pp. 1-8, 2016.

[7] U. Juhardi and Andilala, “Optimalisasi Penjualan Motor Menggunakan Algoritma Particle Swarm Optimization ( PSO ),” Jurnal Media Infotama, vol. 15, no. 2, pp. 71-78, 2019.

[8] D. Ana, R. Wati, and Y. A. Rochman, "Model Penjadwalan Matakuliah Secara Otomatis Berbasis Algoritma Particle Swarm Optimization (PSO)," Jurnal Rekayasa Sistem Industri, vol. 2, no. 1, pp. 22-31, 2013.

[9] A. Setiawan, L. W. Santoso, and R. Adipranata, "Penerapan Algoritma Particle Swarm Optimization ( PSO ) untuk Optimisasi Pembangunan Negara dalam Turn Based Strategy Game," Jurnal Infra, vol. 7, no. 1, pp. 249-255, 2019.

[10] Ridwansyah and E. Purwaningsih, "Particle Swarm Optimization Untuk Meningkatkan Akurasi Prediksi Pemasaran Bank," Jurnal PILAR Nusa Mandiri, vol. 14, no. 1, pp. 83-88, 2018.

[11] R. Maulida, "Prediksi Kelulusan Mahasiswa Tepat Waktu dengan Algoritma C4 . 5 dengan Particle Swarm Optimization pada Univeristas XYZ,' Journal of Artificial Intelligence and Innovative Applications, vol. 1, no. 3, pp. 138-144, 2020.

[12] M. Zainuddin, "Metode Klasifikasi Berbasis Particle warm Optimazion (PSO) untuk Prediksi Kelulusan Tepat Waktu Mahasiswa," Jurnal Ilmiah Teknologi Informasi Asia, vol. 13, no. 1, pp. 1-12, oct 2018.

[13] H. Hendra, M. A. Azis, and S. Suhardjono, "Analisis Prediksi Kelulusan Mahasiswa Menggunakan Decission Tree Berbasis Particle Swarm Optimization,” Jurnal Sisfokom (Sistem Informasi dan Komputer), vol. 9, no. 1, pp. 102-107, mar 2020.

[14] R. Ridwan, H. Lubis, and P. Kustanto, "Implementasi Algoritma Neural Network dalam Memprediksi Tingkat Kelulusan Mahasiswa," JURNAL MEDIA INFORMATIKA BUDIDARMA, vol. 4, no. 2, pp. 286-293, apr 2020.

[15] R. L. Rose, B. D. A. Selvi, and R. L. R. Singh, "Development of Hybrid Algorithm Based on PSO and NN to Solve Economic Emission Dispatch Problem,” Circuits and Systems, vol. 07, no. 09, pp. 2323-2331, 2016.

[16] A. Alrijadjis, "Implementasi Metode PSO-LDW untuk Optimasi Kontroler PID Pada Plant Orde Tinggi," in Industrial Electronic Seminar, 2010, pp. 1-4.

[17] M. N. Alam, “Codes in MATLAB for Particle Swarm Optimization,” ResearchGate, vol. 8, pp. 1-10, 2016.

[18] H. Moayedi, A. Osouli, H. Nguyen, and A. S. A. Rashid, "A novel Harris hawks' Optimization and K-Fold Cross-Validation Predicting Slope Stability,” Engineering with Computers, vol. 37, no. 1, pp. 369-379, jan 2021.

[19] S. Ruuska, W. Hämäläinen, S. Kajava, M. Mughal, P. Matilainen, and J. Mononen, "Evaluation of The Confusion Matrix Method in The Validation of An Automated System for Measuring Feeding Behaviour of Cattle," Behavioural Processes, vol. 148, pp. 56-62, mar 2018. 